\title{
Oesophageal stricture associated with emepronium bromide therapy
}

\author{
I. W. Fellows \\ M.B., M.R.C.P.
}

\author{
A. L. OGILvie \\ M.B., M.R.C.P.
}

\author{
M. AtKinson \\ M.D., F.R.C.P. \\ University Hospital, Queen's Medical Centre, Nottingham
}

\begin{abstract}
Summary
Emepronium bromide, a drug used to control urinary frequency, has been reported as causing oesophageal ulceration but not stricture formation. This paper presents 3 cases in which the use of emepronium bromide preceded development of an oesophageal stricture and suggests that the drug played a causative role.
\end{abstract}

\section{Case reports}

\section{Case 1}

A 50-year-old woman, with a 6-year history of multiple sclerosis causing spastic paraparesis of the lower limbs, presented with a 2-month history of dysphagia for solids, retrosternal pain and $12.7 \mathrm{~kg}$ weight loss. She was taking baclofen, carbamazepine, dihydrocodeine and dothiepin and emepronium bromide $100 \mathrm{mg}$ thrice daily over the previous 4 years for urinary frequency. Examination revealed a thin woman, with signs of multiple sclerosis.

Barium swallow showed a smooth stricture at the junction of the upper and middle third of the oesophagus.

Endoscopy revealed ulceration and severe inflammation of the oesophagus at $25 \mathrm{~cm}$ from the alveolar margin where the oesophagus was narrowed to about $10-\mathrm{mm}$ diameter. In the lower $2-\mathrm{cm}$ of the oesophagus there was mild reflux oesophagitis and a small hiatus hernia.

The emepronium was stopped with good symptomatic relief during the next year.

\section{Case 2}

An 89-year-old woman presented with a one-year history of dysphagia for solids and interscapular pain. She had had heartburn for many years. She was taking ibuprofen, salbutamol, cimetidine and emepronium bromide $100 \mathrm{mg}$ twice daily over the previous 12 months because of her urinary frequency. Examination showed osteo-arthritis of knees and ankles but was otherwise normal.
Barium swallow showed a small fixed hiatus hernia with a stricture above it and an ulcer crater therein.

Endoscopy showed a 5-mm diameter benign stricture at $33 \mathrm{~cm}$ from the alveolar margin; the stricture was $1 \mathrm{~cm}$ long and was ulcerated. Below it was a hiatus hernia. The stricture was dilated, the emepronium stopped and she was given cimetidine and Asilone gel. One further dilatation was needed 4 months later but she has swallowed well for the last 6 months.

\section{Case 3}

A 74-year-old woman presented with progressive dysphagia for solids for a few weeks and mild heartburn. She was taking Solpadeine (paracetamol $500 \mathrm{mg}$, codeine phosphate $8 \mathrm{mg}$, caffeine $30 \mathrm{mg}$ ) for backache and emepronium bromide tablets, which she swallowed dry, for several weeks because of urinary frequency.

Barium swallow showed a small hiatal hernia and gastro-oesophageal reflux, but at endoscopy a 4$\mathrm{mm}$ diameter ulcerated stricture was found in the oesophagus at $17 \mathrm{~cm}$ from the alveolar margin. After dilatation endoscopy revealed mild reflux oesophagitis in the lower oesophagus and a small hiatus hernia. Emepronium bromide was stopped and she was given cimetidine, metoclopramide and Asilone gel. One further dilatation was needed 2 months later but her swallowing has been normal for the last 4 months.

\section{Discussion}

Emepronium bromide is a quaternary ammonium compound with anticholinergic effects, blocking transmission at autonomic ganglia and postganglionic parasympathetic synapses (Collins et al., 1979). Its formulation as Cetiprin includes a swelling agent which has hygroscopic qualities encouraging its adherence to mucosae (Pilbrant, 1977), particularly if swallowed dry. 
It has been reported as causing oral ulceration if sucked (Strouthidis, Mankikar and Irvine, 1972) and many papers cite its association with oesophageal ulcers (Collins et al., 1979; Shepperd, 1977) but no case has been observed to progress to stricture formation. Oesophageal ulceration usually presents as retrosternal pain on swallowing and resolves quickly once the tablets are withdrawn. Two explanations have been advanced to account for the injury: a direct toxic effect on the mucosa (Strouthidis et al., 1972), or an anticholinergic effect promoting gastro-oesophageal reflux (Shepperd, 1977). The fact that lesions characteristically occur in the upper oesophagus suggests that reflux is not their major cause.

These 3 cases showed not only ulceration but also stricture formation, sufficient to warrant dilatation in 2 of them. Cases 1 and 3 showed high oesophageal ulceration of the type seen after emepronium, while case 2 had a lower oesophageal stricture. All 3 patients had a hiatal hernia and evidence of gastro-oesophageal reflux. The first patient was taking other drugs but the fact that her symptoms resolved when only emepronium bromide was stopped suggests this as the underlying cause. The other 2 patients had more severe strictures and might not be expected to improve in the rapid fashion associated with simple ulceration. It is thought that emepronium bromide played a signifi- $\frac{a}{c}$ cant part in causing these strictures and caution in the use of this drug is recommended, particularly in $\stackrel{0}{\rightarrow}$ the presence of gastro-oesophageal reflux or ab- $\overline{0}$ normal oesophageal motility which impairs oeso- 등 phageal emptying so allowing tablets to remain in $\frac{\bar{\rho}}{\frac{1}{2}}$ the oesophagus for long periods (Evans and Roberts, $\stackrel{\otimes}{\circ}$ 1976). Patients should be carefully instructed to follow the manufacturers' advice to take the drug ${ }^{\text {es }}$ with a reasonable volume of liquid and should not $\vec{\circ}$ adopt the supine position immediately after in- $\overrightarrow{\vec{\omega}}$ gestion.

\section{References}

Collins, F.J., Matthews, H.R., Baker, S.E. \& Strakova, i J.M. (1979) Drug-induced oesophageal injury. British Medical Journal, 1, 1973.

Evans, K.T. \& RoberTs, G.M. (1976) Where do all the जv tablets go? Lancet, ii, 1237. PILbRant, A.K.E. (1977) Ulceration due to emepronium 윽
bromide tablets. Lancet, i, 749 .

SHEPPERD, H.W.H. (1977) Iatrogenic reflux oesophagitis. Journal of Laryngology and Otology, 91, 171.

Strouthidis, T.M., Mankikar, G.D. \& IRVINE, R.E. (1972) Ulceration of mouth due to emepronium bromide. Lancet, i, 72. 